\title{
ANTIFUNGAL ACTIVITY OF EXTRACTS AGAINST Colletotrichum SPECIES IN HARVESTED CHILI
}

\author{
NURUL FAZIHA IBRAHIM*, WONG KAH YIN, NUR HADINA SALEH, \\ FAUZIAH TUFAIL AHMAD and SUHAIZAN LOB \\ Faculty of Fisheries and Food Science, Universiti Malaysia Terengganu, \\ 21030 Kuala Nerus, Terengganu, Malaysia \\ *E-mail:nurulfaziha@umt.edu.my
}

Accepted 10 December 2020, Published online 25 December 2020

\begin{abstract}
Chili is an important vegetable fruit but is commonly attacked by anthracnose disease during field or storage. A current practical method to control this disease is through synthetic fungicides. Although it shows the effective result, repetitive application of chemical fungicides may build up resistant pathogens, expose the risk to human health, and be regarded as not eco-friendly to the environment. This study aimed to evaluate the antifungal activity of several extracts and their potential to control Colletotrichum sp. in harvested chili. For this purpose, several plant extracts namely garlic, ginger, dragon fruit peel (DFP), and milk were used with the concentration ranged from 5 to $20 \%$. All these extracts and milk were tested through in vitro antifungal assay and in vivo antifungal assay directly on the detached chili. The results show that garlic, ginger, and DFP were able to significantly inhibit the fungal pathogen of Colletotrichum sp. through in vitro study with $p<0.05$. Based on in vivo study, the only chili treated with $20 \%$ garlic extract, $20 \%$ ginger extract, and fungicide recorded a significantly lower percentage of disease severity (ds) as compared to the other extracts. Both $20 \%$ garlic and $20 \%$ ginger extracts showed good potential to inhibit the fungal pathogen. Therefore, the application of natural extracts should be focused and practically used as a control strategy in integrated pest management for plant disease, especially in chili production. This control measure is expected to reduce yield losses, operational cost while mitigating the environmental contamination due to overdose chemical residue.
\end{abstract}

Key words: Chili; extracts, anthracnose, growth inhibition, disease severity

\section{INTRODUCTION}

Chili belongs to the family Solanaceae from the genus Capsicum and consists of 20 to 25 species. Among these, the major production is Capsicum annuum followed by C. pubescens (Sahitya et al., 2014). India was considered as the world's largest producer and exporter of chili followed by China, Bangladesh, and Peru (Hussain \& Abid, 2011). Chili is not only important as a food ingredient in many dishes or culinary application but also contributes as a raw material in pharmaceutical industries, cosmetics, preparation of oleoresin and other industrial resources due to its high nutritional value, and medicinal properties which have a diverse application (Hussain \& Abid, 2011). Besides that, various health benefit can be obtained from chili such as it decreases platelet aggregation, enhance

* To whom correspondence should be addressed. blood circulation, cut down calories by boosting thermogenesis, diminish cancer risk by inhibiting the carcinogens from binding to DNA and lessen pain by releasing endorphins in the body (Sahitya et al., 2014).

According to Hussain and Abid (2011), the occurrence of pests and diseases during chili plantation has led to heavy losses in its production. Fungi, bacteria, viruses, and nematodes are among severe threats to the chili crop. Also, poor transportation practices and storage facilities contribute to severe post-harvest losses in many developing countries (Saxena et al., 2016). Anthracnose, Cercospora (frogeye) leaf spot, charcoal rot, Choanephora blight (wet rot), damping-off root rot, downy mildew, Fusarium stem rot, Fusarium wilt, gray leaf spot, gray mold, Phytophthora blight, powdery mildew, southern blight, Verticillium wilt, and white mold are among pre-harvesting fungal diseases in chili crop. 
Colletotrichum spp. causing chili anthracnose is considered to be the major fungal disease problem in chili production. Anthracnose causes quantitative and qualitative losses of the crop in the fields as well as in the storage every year (Musakhan \& Zacharia, 2017). The anthracnose disease can be detected on mature fruits and affecting pre-harvest and post-harvest fruit loss (Sahitya et al., 2014). Generally, chili production is severely affected by the outbreak of Colletotrichum spp. causing anthracnose disease. The occurrence of this disease can reduce crop yield production between 10 to $80 \%$. As a consequence, the profit margin earned by farmers in tropical developing countries such as Pakistan, India, Thailand, Mexico, and Malaysia has decreased (Than et al., 2008; Shahbazi et al., 2014). In several conditions, it can cause economic losses due to lower fruit quality and affecting its marketability. The infected fruits are not toxic to humans or animals but it is considered unfit for human consumption due to the production of unpleasant color and taste caused by anthracnose (Elmabrok, 2014).

The most common and practical method to control anthracnose diseases is through the use of synthetic fungicides (Ajithkumar et al., 2014). Although it shows the effective result, repetitive application of chemical fungicides may build up resistant pathogens, expose the risk to human health, and be regarded as not eco-friendly to the environment (Shahbazi et al., 2014). Human and animals are at high risk if they consume agricultural produces or water that contaminated with fungicides residue (Aktar et al., 2009). The chemical residues that leftover on the products or leaching into the soil after repetitive application may also harm human health and the environment. Montri et al. (2009) reported that fungicides application particularly in small-holder farming systems is not sustainable due to the high cost and risks to the environment. This study was conducted to evaluate the efficacy of several natural extracts as a biological control against Colletotrichum sp. in harvested chili.
Application of organic extract such as garlic, ginger, dragon fruit peel extracts is hoped to become alternative control measures in storage chili and reduce the occurrence of chili anthracnose in the cultivation area. Besides that, it can ensure more environmentally friendly disease management while ensuring the safety and security of the food supply.

\section{MATERIALS AND METHODS}

\section{Fungal pathogen}

One fungal pathogen namely Colletotrichum sp. labeled as UMT FP5 was obtained from the culture collection at Universiti Malaysia Terengganu. The isolate was isolated from anthracnose disease on chili pod and has been identified using morphological characteristics (Figure 1).

\section{Preparation of extracts}

There were four extracts used for in vitro study namely milk, ginger, garlic, and dragon fruit peel (DFP). Milk was prepared by diluting the UHT whole milk with molten potato dextrose agar (PDA) into $5 \%, 10 \%, 15 \%$, and $20 \%(\mathrm{v} / \mathrm{v})$. For garlic, ginger, and dragon fruit peel (DFP), these materials were peeled, washed with distilled water, and air-dried. Then, the garlic or ginger was crushed into fine particles using a blender before shaken the mixture for $24 \mathrm{hr}$ in an incubator shaker at room temperature. Finally, the extract was sieved through Whatman No. 1 filter paper before diluted into $5 \%, 10 \%, 15 \%$, and $20 \%(\mathrm{v} / \mathrm{v})$ mixed with molten PDA. For DFP, the material was mixed and macerated with ethanol at a 1:20 ratio for 7 days. Then the extract was filtrated through Whatman No. 1 filter paper before rotorevaporated the supernatant by using the rotary evaporator to obtain the crude extracts. Then, the crude extract was diluted into $5 \%$ and $20 \%$ with molten PDA. For positive control, the fungicide (Kencozeb M45) was diluted with molten PDA according to agriculture standard, $2.5 \mathrm{~g} \mathrm{~L}^{-1}$.

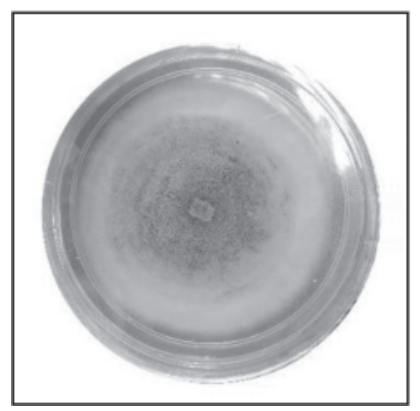

(a) Upper colony

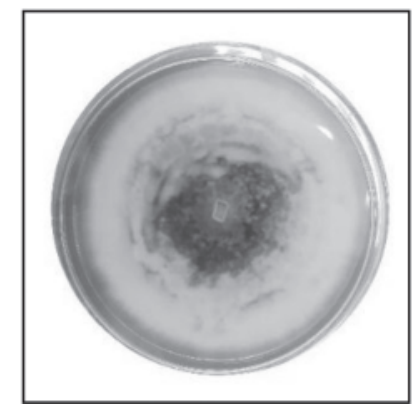

(b) Colony pigmentation

Fig. 1. Upper colony and colony pigmentation of pathogenic Colletotrichum sp. (UMT FP5). 
For in vivo study, all the extracts namely milk, ginger, garlic, and dragon fruit peel (DFP) obtained from in vitro study were diluted with sterile distilled water and mixed with tween 80 as a surfactant. Only selected treatments namely $10 \%$ milk, $20 \%$ garlic, $5 \%$ ginger, $20 \%$ ginger, $5 \%$ DFP, and 20\% DFP were used in this study. The positive control was prepared by diluted the fungicide (Kencozeb M45) with sterile distilled water according to the agriculture standard, $2.5 \mathrm{~g} \mathrm{~L}^{-1}$.

\section{In vitro study using poison plate technique}

The poison plate technique was used to evaluate the effect of extracts on radial colony growth of fungal pathogen through in vitro study. For this purpose, PDA was mixed with different concentrations of garlic extract, UHT whole milk solution, ginger extract, dragon fruit peel (DFP) extract, and fungicide (Kencozeb M45) at different concentrations ranged from $5 \%$ to $20 \%$ before pouring into a petri dish. Untreated PDA plates were served as a negative control. After solidification, the PDA was inoculated with 7-days old pathogenic Colletotrichum sp. (UMT FP5) at the center of the plate. All the inoculated plates were incubated at room temperature $\left(28 \pm 2^{\circ} \mathrm{C}\right)$ and the radial colony diameter was recorded every day until the negative control plate was fully covered with fungal isolate. The colony diameter was measured at the bottom of the Petri dishes. Then, the measurement was converted into a percentage of fungal inhibition (GI) using the formula:

Percentage of fungal inhibition:

$$
\% \text { fungal inhibition }(\mathrm{GI})=\frac{\mathrm{X}-\mathrm{Y}}{\mathrm{X}} \times 100
$$

Where,

$\mathrm{X}=$ Mycelium growth diameter on the control plate. $\mathrm{Y}=$ Mycelium growth diameter on treated plates.

\section{In vivo study on chili pod}

For in vivo study, the efficacy of extracts on the detached chili pod was tested by dipping the healthy chili pod into different concentrations of extracts. For this experiment, only several treatments were selected namely $10 \%$ milk, $20 \%$ garlic, $5 \%$ ginger, 20\% ginger, 5\% DFP, 20\% DFP, and fungicide. Untreated chili was served as a negative control. After dipping, the chili pods were air-dried before inoculated with pathogenic Colletotrichum sp. (UMT FP5). All the inoculated chili pods were placed in a plastic container and incubated at room temperature. The appearance of symptoms was scored from 0 to 5 and converted into a percentage of disease severity using the following formula. All the incubated chilies were evaluated at 3 days interval for 15 days.

$\%$ Disease severity $(\mathrm{DS})=\frac{\Sigma(n \times \text { disease scale })}{\mathrm{dmax} \times \Sigma \mathrm{n}} \times 100$

Where;

$\mathrm{n}=$ number of replicate.

$\operatorname{dmax}=$ maximum scale.

\section{RESULTS AND DISCUSSION}

Finding natural products with antimicrobial properties that contain a spectrum of secondary metabolites such as alkaloids, quinones, flavonoids, glycosides, saponins, tannins, and terpenoids are very active particularly related to pest management. In this study, several plant extracts with different concentrations ranged from $5 \%$ and $20 \%$ showed a different effect on pathogenic Colletotrichum sp. (UMT FP5) through in vitro and in vivo studies. According to Gahukar (2012), the ability of extracts to inhibit the fungal growth depended on the concentration of bioactive compounds in plant species which depends on the environmental conditions and the pathosystem.

Figure 2 shows the percentage of fungal growth inhibition using different types and concentrations of extracts based on in vitro study. There was a variable percentage of fungal growth inhibition (GI) (GI $=2.78 \%$ to $61.11 \%$ ) against Colletotrichum sp. (UMT FP5) in PDA treated with different types and concentrations of extracts. All the extracts were significantly able to inhibit Colletotrichum sp. (UMT FP5) except for the milk. Among the treatments, fungicide (Kencozeb M45) that served as positive control showed the highest percentage of GI $(88.10 \%)$, followed by $20 \%$ garlic (GI $=61.11 \%), 20 \%$ dragon fruit peel (DFP) $(\mathrm{GI}=52.10 \%), 20 \%$ ginger $(\mathrm{GI}=47.92 \%), 15 \%$ ginger $(\mathrm{GI}=45.24 \%), 5 \%$ DFP (GI=36.25\%), 10\% garlic $(\mathrm{GI}=34.52 \%)$ and $5 \%$ garlic $(\mathrm{GI}=29.76 \%)$. Milk extracts did not significantly inhibit the Colletotrichum sp. which showed lower GI ranged between $2.7 \%$ to $3.97 \%$.

Only several extracts were selected for in vivo study. Based on the result, chili pod treated with $20 \%$ ginger extract showed the lowest disease severity (DS), $46.67 \%$ followed by $20 \%$ garlic, fungicide, $20 \%$ DFP, $10 \%$ milk, $5 \%$ DFP, and $5 \%$ ginger (Figure 3). Among these, only 20\% ginger, $20 \%$ garlic, and fungicide can significantly inhibit Colletotrichum sp. (UMT FP5) with lower DS ranged from $47.67 \%$ to $53.33 \%$ compared to untreated chili pod. During incubation day, the chili pods treated with milk, garlic, ginger, DFP, and Kencozeb M45 


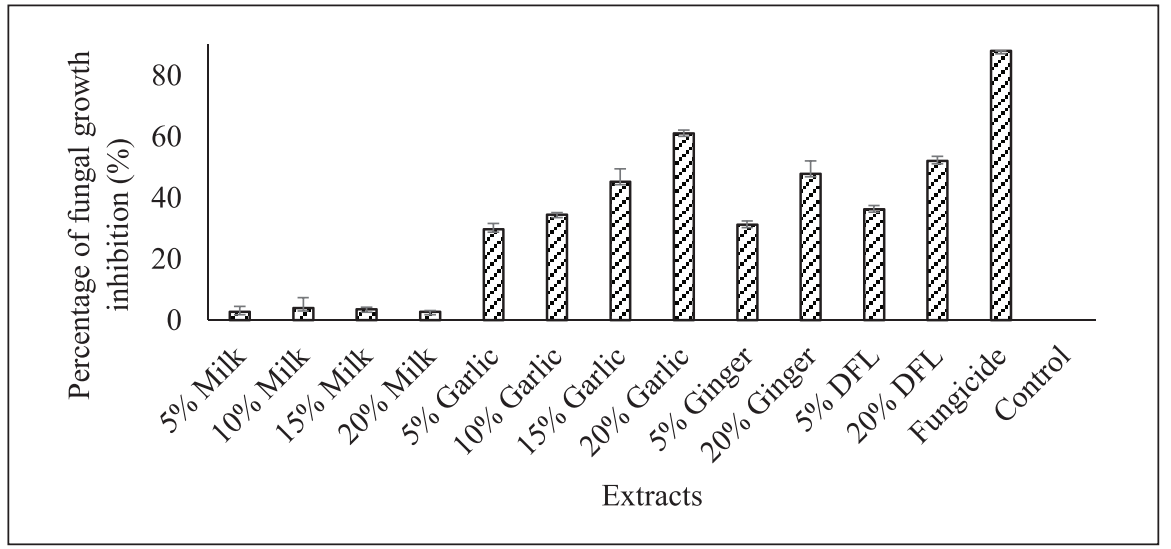

Fig. 2. Percentage of fungal growth inhibition through in vitro study using different types and concentrations of extracts.

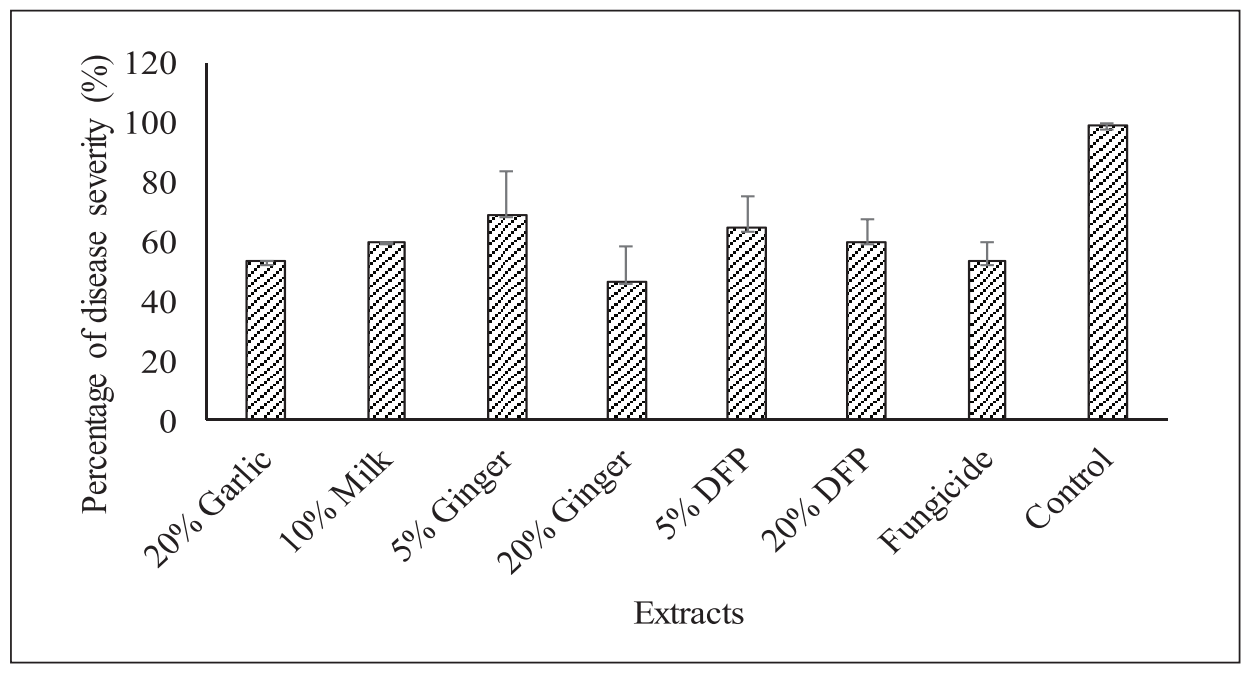

Fig. 3. Percentage of disease severity on inoculated chili dipped with several extracts and fungicide.

did not show any symptoms until day 5 . However, the anthracnose symptoms initially appeared on day 6 on the treated chili pod while on day 3 on the untreated chili pod. The inoculated area appeared as small, brown, necrotic spots on the infected chili pods (Figure 4). On day 12, the lesion became darker and formed large, sunken necrotic areas with many black acervuli on the surface.

The results demonstrated that increasing the concentration of extract will directly increase the antifungal activity against pathogenic Colletotrichum sp. (UMT FP5). Both 20\% garlic and $20 \%$ ginger extracts can significantly inhibit the fungal pathogen through in vitro and in vivo studies. However, 20\% DFE can only significantly inhibit the fungal pathogen through in vitro study but the result was not significant using in vivo technique. Dubey (2013) reported that $20 \%$ garlic extract showed the highest inhibition (71.6\%) towards the mycelial growth of $C$. dematium var. truncate compared to $5 \%$ garlic, $5 \%$ and $20 \%$ of aloe vera,

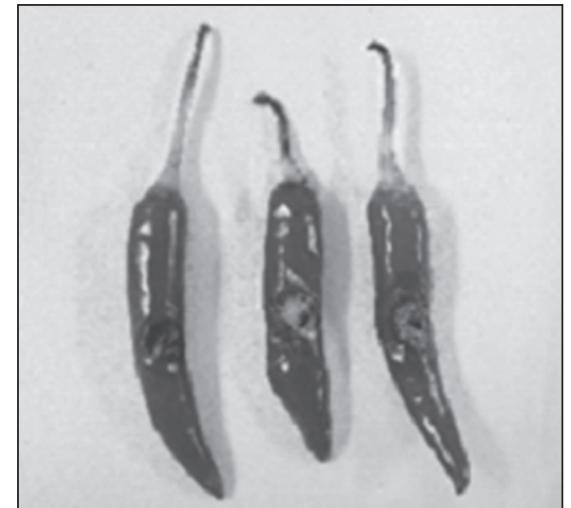

Fig. 4. Appearance of the lesion due to anthracnose disease on inoculated chili pod.

bhang, neem, onion, tulsi and ginger solution respectively. Also, garlic extract can inhibit the growth and sporulation of C. capsici from chili anthracnose as compare to control (Musakhan \& Zacharia, 2017). According to Shovan et al. (2008), 
garlic extract was found to be very effective in controlling the anthracnose disease in different crops. Ginger has several volatile compounds such as á-pinene, borneol, camphene, and linalool which responsible for antimicrobial activities (Liu et al., 2017). According to Chen et al. (2018), ginger oleoresin effectively inhibited mycelial growth and spore germination of $P$. microspore through in vitro study. Liu et al. (2017) reported that antifungal activities of crude extracts including ginger made by hot water extract effectively inhibited Phoma exigua, Fusarium nygamai, and $R$. solani through in vitro technique. From this, hot water extracts from ginger showed the best antifungal activities. Mukherjee (2011) reported that $70 \%$ concentration of ginger extract can inhibit mycelial growth with $\mathrm{GI}=41.04 \%$ and $60 \%$ ginger extract can inhibit mycelial growth with GI $=37.99 \%$. A study conducted by Stangarlin et al. (2011) reported that $20 \%$ ginger aqueous extract can effectively inhibit the mycelial growth of Sclerotinia sclerotiorum. A lack of study has been reported on dragon fruit peel extract as an antifungal agent. Ismail et al. (2017) reported that dragon fruit extract rich in phytoalbumins which have great high antioxidant and antifungal activities due to its high phenolic content (15.92 mg gallic acid/g). Also, the chemical composition contains in dragon fruit extract such as polyphenols, flavonoids, and tannins have shown very promising results in combating bacteria and fungus (Nor Mahani et al., 2012).

\section{CONCLUSION}

Anthracnose on chili is caused by Colletotrichum spp. which may give a huge impact on chili quality and its production. In plant disease management, chemical fungicides have become an important tool in controlling plant diseases. Frequent application of chemical fungicides may raise negative environmental impacts, increase risk towards human exposure to pesticides, and deposition of residues on the fruits. In this study, it may be concluded that the application of natural extracts such as $20 \%$ ginger and $20 \%$ garlic can significantly inhibit through in vitro and in vivo study. Also, the ability of these extracts (20\% ginger and $20 \%$ garlic) to reduce disease severity due to Colletotrichum sp. (UMT FP5) shows its potential to protect chili from anthracnose infection. Hence, the application of natural extract should have a great demand due to safer, alternative, and effective chemotherapeutic agents that act as preventive control methods on disease and pest.

\section{ACKNOWLEDGEMENTS}

The authors are grateful to the sponsor of this research, the Ministry of Higher Education (FRGS RACER VOT 59555) and Universiti Malaysia Terengganu. Our gratitude also goes to all staff for their technical support.

\section{REFERENCES}

Aktar, W., Sengupta, D. \& Chowdhury, A. 2009. Impact of pesticides use in agriculture: their benefits and hazards. Interdisciplinary Toxicology, 2(1): 1-12.

Ajithkumar, K., Savitha, A.S., Biradar, S.A., Rajanna, B. \& Ramesh, G. 2014. Management of powdery mildew and anthracnose diseases of chilli (Capsicum annuum L.). Pest Management in Horticultural Ecosystems, 20(1): 80-83.

Chen, T., Kang, B., Ding, L., Zhang, L., Chen, S. \& Lin, H. 2018. Antifungal activity and action mechanism of ginger oleoresin against Pestalotiopsis microspora isolated from chinese olive fruits. Frontiers in Microbiology, 9: 2583.

Dubey, K.S. 2013. Efficacy of plant extracts in inhibition of radial growth of Colletotrichum dematium var. truncata. Pantnagar Journal of Research, 11(2): 312-314.

Elmabrok, A.S.W. 2014. Lactic Acid Bacteria as Biological Control Against Colletotrichum Capsici and Colletotrichum Gloeosporioides on Chilli Plants (Ph.D). Universiti Sains Islam Malaysia).

Gahukar, R.T. 2012. Evaluation of plant-derived products against pests and diseases of medicinal plants: a review. Crop Protection, 42: 202-209.

Hussain, F. \& Abid, M. 2011. Pest and diseases of chilli crop in Pakistan: A review. International Journal of Biology and Biotechnology, 8(2): 325-332.

Ismail, O.M., Abdel-Aziz, M.S., Ghareeb, M.A. \& Hassan, R.Y. 2017. Exploring the biological activities of the Hylocereus polyrhizus extract. Journal of Innovations in Pharmaceutical and Biological Sciences, 4: 1-6.

Liu, Q., Meng, X., Li, Y., Zhao, C.N., Tang, G.Y. \& Li, H.B. 2017. Antibacterial and antifungal activities of spices. International Journal of Molecular Sciences, 18(6): 1283.

Montri, P., Taylor, P.W.J. \& Mongkolporn, O. 2009. Pathotypes of Colletotrichum capsici, the causal agent of chili anthracnose, in Thailand. Plant Disease, 93(1): 17-20. 
Mukherjee, A., Khandker, S., Islam, M.R. \& Shahid, S.B. 2011. Efficacy of some plant extracts on the mycelial growth of Colletotrichum gloeosporioides. Journal of Bangladesh Agricultural University, 9(1): 43-47.

Musakhan, P.R. \& Zacharia, S. 2017. Effect of neem based plant products and plant extracts against anthracnose of chilli (Capsicum annuum L.). Journal of Pharmacognosy and Phytochemistry, 6(5): 171-174.

Nurmahani, M.M., Osman, A., Hamid, A.A., Ghazali, F.M. \& Dek, M.P. 2012. Antibacterial property of Hylocereus polyrhizus and Hylocereus undatus peelextracts. International Food Research Journal, 19(1): 77.

Sahitya, U.L., Deepthi, S., Kasim, P., Suneetha, P. \& Krishna, M.S.R. 2014. Anthracnose, a prevalent disease in Capsicum. Research Journal of Pharmaceutical, Biological and Chemical Sciences, 5(3): 1583-1604.

Saxena, A., Raghuwanshi, R., Gupta, V.K. \& Singh, H.B. 2016. Chilli anthracnose: the epidemiology and management. Frontiers in Microbiology, 7: 1527.
Shahbazi, P., Musa, M.Y., Tan, G.Y.A., Avin, F.A., Teo, W.F.A. \& Sabaratnam, V. 2014. In vitro and in vivo evaluation of Streptomyces Suppressions against Anthracnose in Chili Caused by Colletotrichum. Sains Malaysiana, 43: 697-705.

Shovan, L.R., Bhuiyan, M.K.A., Begum, J.A. \& Pervez, Z. 2008. In vitro control of Colletotrichum dematium causing anthracnose of soybean by fungicides, plant extracts and Trichoderma harzianum. International Journal of Sustainable Crop Production, 3(3): 10-17.

Stangarlin, J.R., Kuhn, O.J., Assi, L. \& SchwanEstrada, K.R.F. 2011. Control of plant diseases using extracts from medicinal plants and fungi. Science against microbial pathogens: communicating current research and technological advances. Badajoz: Formatex, 2: 1033-1042.

Than, P.P., Prihastuti, H., Phoulivong, S., Taylor, P.W.J. \& Hyde, K.D. 2008. Chilli anthracnose disease caused by Colletotrichum species. Journal of Zhejiang University. Science. B, 9(10): 764-778. 